\title{
CARACTERIZAÇÃO PARCIAL PROBIÓTICA E MOLECULAR DE BACTÉRIAS ÁCIDO LÁCTICAS ISOLADAS DE QUEIJO DE COALHO DA CIDADE DE ARCOVERDE - PERNAMBUCO
}

\author{
Dayane da Silva Santos \\ Priscilla Régia de Andrade Calaça* \\ Ana Lúcia Figueiredo Porto ${ }^{* * *}$ \\ Paulo Roberto Eleutério de Souza ${ }^{* * *}$ \\ Maria Taciana Holanda Cavalcanti ${ }^{* *+*}$
}

\begin{abstract}
RESUMO: 0 conhecimento da biodiversidade das cepas de bactérias ácido lácticas autóctones é muito importante para a produção de queijo de coalho com qualidade, pois as BAL atuam na inibição do crescimento de microrganismos indesejáveis por competição ou pela ação de proteínas antimicrobianas denominadas bacteriocinas por elas sintetizadas. Além dos efeitos probióticos apontados por pesquisas, com benefícios para a saúde humana. Por isso, esse trabalho teve por objetivo a caracterização parcial probiótica de bactérias ácido lácticas isoladas de queijo de coalho da cidade de Arcoverde - Pernambuco. As bactérias ácido lácticas utilizadas foram previamente isoladas do queijo de coalho da cidade de Arcoverde-PE e conservadas sob refrigeração no Centro de Apoio à pesquisa-Cenapesq. Foram usadas 11 cepas bacterianas diferentes para os testes. As BAL foram submetidas ao teste de resistência ao valor de pH baixo, resistência à presença de sais biliares, atividade antagonista e caracterização molecular, seguindo parâmetros da Agência Nacional de Vigilância Sanitária. Das 11 bactérias isoladas da cidade de Arcoverde-PE apenas duas foram eficientes para a maioria dos testes e identificadas como Enterococcus, demonstrando o seu potencial probiótico. Portanto, percebemos que bactérias isoladas do queijo de coalho pernambucano representam importante fonte de microrganismos benéficos para a tecnologia de alimentos e saúde humana e animal.
\end{abstract}

PALAVRAS-CHAVE: Probióticos; Tecnologia de alimentos; Saúde; Microrganismos.

\section{PARTIAL PROBIOTIC AND MOLECULAR CHARACTERIZATION OF LACTIC ACID BACTERIA ISOLATED FROM CHEESE CURDS IN ARCOVERDE, BRAZIL}

\begin{abstract}
Investigation on the biodiversity of autochthonous lactic acid bacteria is highly relevant for the manufacture of quality cheese curds. In fact, lactic acid bacteria (LAB) impair the growth of undesirable microorganism due to competition or to bacteriocin-synthetized antimicrobial proteins. Research has also indicated probiotic effects with great health benefits. Current paper provides partial probiotic characterization of lactic acid bacteria isolated from cheese curds in the town of Arcoverde PE Brazil. Lactic acid bacteria were previously isolated from cheese curds in the town of Arcoverde and refrigerated at the Cenapesq Research Center. Eleven different bacterial strains were used. LAB were subjected to resistance test with low pH, resistance to biliary salts, antagonistic activity and molecular characterization according to parameters by the National Sanitary Vigilance Agency. Only two out of the eleven bacteria were efficient for most tests, identified as Enterococcus, with probiotic potential. Results show that bacteria isolated from cheese curds are an important source of good microorganisms for food technology and for human and animal health.
\end{abstract}

KEYWORDS: Probiotics; Food Technology; Health; Microorganisms.

\footnotetext{
Graduanda em Licenciatura Plena em Ciências Biológicas - Departamento de Biologia. Universidade Federal Rural de Pernambuco (UFRPE), Brasil. E-mail: santos.dhay08@gmail.com

** Doutoranda do Programa de Pós Graduação em Biociência Animal- Departamento de Morfologia e Fisiologia Animal. Universidade Federal Rural de Pernambuco (UFRPE), Brasil.

${ }^{* * *}$ Docente titular do departamento de morfologia e fisiologia animal da Universidade Federal Rural de Pernambuco (UFRPE). Pesquisador da UFRPE, Brasil.

${ }^{*}$ Docente do Departamento de Genética. Universidade Federal Rural de Pernambuco (UFRPE), Brasil.

${ }^{* * * * *}$ Docente do Departamento de Anatomia e Fisiologia Animal. Universidade Federal Rural de Pernambuco (UFRPE), Brasil.
} 


\section{INTRODUÇÃo}

As bactérias ácido lácticas (BAL) compreendem um grupo de microrganismos com representantes geneticamente distintos, cuja principal característica é a produção do ácido lático (AXELSSON, 1998). Outras características podem ser destacadas como a ausência de patogenicidade, que são as Gram-positivas, não formam esporos de resistência, catalase negativas, acidófilas, não possuem flagelo e são anaeróbias facultativas (HOFVENDAHL; HÄGERDAL, 2000).

Pelo seu potencial tecnológico, crescente nos últimos tempos, as BAL são utilizadas na tecnologia de alimentos e na segurança microbiológica de alimentos fermentados, dentre eles o queijo de coalho (SETTANNI; CORSETTI, 2010). Este, um produto tipicamente nordestino, é normalmente produzido de forma artesanal a partir do leite rico em bactérias ácido láticas, que participam das características organolépticas do queijo, importantes na textura e aroma final do produto.

Pernambuco é o maior Estado produtor de queijo de coalho do nordeste, concentrando-se na região do agreste (a denominada bacia leiteira), onde está localizada a cidade de Arcoverde, sendo uma importante fonte de renda para a população (ESCOBAR, 2001). Na região, as BAL são utilizadas há mais de 150 anos, porém sem nenhum critério de seleção (CAVALCANTE et al., 2008). Contudo, o conhecimento da biodiversidade das cepas de bactérias ácido lácticas autóctones é muito importante para a produção de queijo de coalho com qualidade, pois as BAL atuam na inibição do crescimento de microrganismos indesejáveis por competição ou pela ação de proteínas antimicrobianas denominadas bacteriocinas por elas sintetizadas (DEEGAN et al., 2006).

Estudos ainda apontam seu potencial probiótico na restauração da microbiota lesada por antibióticos e papel antagonista diante de bactérias patogênicas (DIAS, 2014). Muitos dos microrganismos probióticos são bactérias ácido lácticas que incluem os gêneros Lactobacillus, Bifidobacterium, Enterococcus, Lactococcus, Leuconostoc, Pediococcus, Sporolactobacillus e Streptococcus (OLIVEIRA-
SERQUEIRA; RIBEIRO; GOMES, 2008).

0 potencial probiótico das bactérias ácido lácticas é alvo de diversas pesquisas. Atualmente, a palavra "probiótico" é definida pela Organização de Agricultura e Alimentação e pela Organização Mundial da Saúde (FAO/WHO) como microrganismos vivos que, quando administrados em quantidade apropriada, conferem benefícios à saúde do hospedeiro, pois melhoram 0 equilíbrio microbiano intestinal (FOOD AND AGRICULTURE ORGANIZATION OF THE UNITED NATIONS; WORLD HEALTH ORGANIZATION, 2002).

No Brasil, a Agência Nacional de Vigilância Sanitária (ANVISA, 2008) determina parâmetros para 0 enquadramento de um produto como probiótico, como concentração mínima de microrganismos probióticos no produto $\left(10^{-8}\right.$ a $\left.10^{-9} \mathrm{UFC} / \mathrm{mL}\right)$ comprovada até 0 final da validade do produto, resistência a sais biliares e acidez gástrica da cultura comprovada por testes laboratoriais, utilização de uma das espécies recomendadas ou de uma espécie fora da lista que seja comprovadamente probiótica.

0 conhecimento da biodiversidade das cepas de bactérias ácido lácticas autóctones é muito importante para a produção de queijo de coalho com qualidade, selecionando as bactérias que apresentam maior atividade antimicrobiana, e garantam maior durabilidade ao produto e principalmente, que tenham comprovados os benefícios promotores da saúde humana com os efeitos probióticos (BERESFORD et al., 2001).

Portanto, o estudo de bactérias ácido lácticas com potencial probiótico é imprescindível, pois as vantagens à saúde humana e animal são diversas. Além disso, 0 isolamento das BAL de uma fonte de baixo custo, confiável, acessível e bastante consumida como o queijo de coalho, um produto tipicamente nordestino permite maior acesso aos probióticos e a seus benefícios. A análise de culturas de BAL "selvagens" poderia também disponibilizar ao mercado novas cepas probióticas. 


\section{MATERIAIS E MÉTODOS}

As bactérias ácido lácticas utilizadas foram previamente isoladas do queijo de coalho da cidade de Arcoverde-PE e conservadas sob refrigeração no Centro de Apoio à pesquisa-Cenapesq. Foram usadas 11 cepas bacterianas diferentes para os testes. As BAL foram submetidas ao teste de resistência ao valor de pH baixo, resistência à presença de sais biliares, atividade antagonista e caracterização molecular.

\subsection{RESISTÊNCIA AO VALOR DE pH BAIXO}

A pesquisa foi realizada de acordo com Argyri et al. (2013), com culturas após 18 horas de crescimento em caldo MRS, ajustada para $10^{8} \mathrm{UFC} / \mathrm{mL}$. A cultura foi centrifugada $\left(10.000 \mathrm{xg}, 5\right.$ minutos, $\left.4^{\circ} \mathrm{C}\right)$, lavada duas vezes com tampão fosfato salino (PBS 1M) $(\mathrm{pH} 7,2)$. Logo após, foi ressuspendida em solução PBS com pH ajustado para 2,5 , incubadas a $37^{\circ} \mathrm{C}$ por 0,1 e 3 horas. A seguir, a resistência e a viabilidade das colônias foram analisadas a partir do crescimento em MRS ágar com incubação a $37^{\circ} \mathrm{C}$ por 24 horas. 0 experimento foi realizado em duplicata. 0 número de células viáveis foi expresso em UFC/ $\mathrm{mL}^{-1}$.

\subsection{RESISTÊNCIA À PRESENÇA DE SAIS DE BILE}

Foi realizada de acordo com Argyri et al. (2013), com culturas após 18 horas de crescimento em caldo MRS, ajustada para $10^{8} \mathrm{UFC} / \mathrm{mL}$. A cultura foi centrifugada $\left(10.000 \mathrm{xg}, 5\right.$ minutos, $\left.4^{\circ} \mathrm{C}\right)$, lavada duas vezes com tampão fosfato salino (PBS 1M) (pH $7,2)$, ressuspendida em solução PBS ajustado para pH 8,0, contendo 0,5\% (peso/volume) de sais de bile (Himedia $^{\circledR}$ ), incubação a $37^{\circ} \mathrm{C}$ por 0,2 e 4 horas, A resistência e a viabilidade das colônias foram analisadas pelo crescimento em MRS ágar a $37^{\circ} \mathrm{C}$ por 24h. 0 experimento foi realizado em duplicata. 0 número de células viáveis foi expresso em UFC/ $\mathrm{mL}^{-1}$.

\subsection{ATIVIDADE ANTIMICROBIANA}

Os testes foram realizados em triplicata na microplaca de fundo chato com 96 poços, onde foi analisado 0 controle negativo (150 $\mu \mathrm{L}$ de meio estéril), 0 controle positivo (150 $\mu \mathrm{L}$ de meio estéril acrescido de $1 \mu \mathrm{L}$ da bactéria indicadora, ajustada para uma concentração de $10^{7} \mathrm{UFC} / \mathrm{mL}$ ) e 0 sobrenadante do cultivo das BAL na presença da bactéria indicadora. Sendo assim, $150 \mu \mathrm{L}$ do sobrenadante foram diluídos, conforme o método de Mayr-Harting et al. (1972), para analisar a CMI do sobrenadante frente aos patógenos, nas proporções de 1:2, 1:4, 1:8, 1:16, 1:32, 1:64, 1:128 e 1:256.

Após inóculo em placa, a cultura foi incubada a $37^{\circ} \mathrm{C}$ por 24 horas, seguida de leitura sob $595 \mathrm{~nm}$ de Densidade Óptica (D.0.). As médias dos valores de D.0. ${ }_{595}$ obtidas foram traçadas em função das concentrações iniciais do sobrenadante da BAL, após descontar a média dos valores de D. $_{{ }_{595}}$ do meio estéril. A CMI foi considerada como sendo a menor concentração de sobrenadante em que não houve crescimento significativo da bactéria indicadora, por comparação com o controle negativo. Portanto, a atividade foi definida como a recíproca da diluição mais elevada mostrando uma inibição das bactérias indicadoras multiplicada por 100 para expressar os resultados como Unidades Arbitrárias em mililitro (UA/ $\mathrm{ml}^{-1}$ ). Entretanto, para correlacionar a concentração de BAL, a equação, segundo Castillo (2013), foi determinada com UA em relação à última diluição em que havia inibição, corrigida para $1 \mathrm{~mL}$. A equação expressa 0 valor de $U A / m L$, em que $(P)$ significa 0 volume depositado na microplaca, (D) 0 número de diluições e (n) o número da diluição que não apresentou inibição:

$\mathrm{AU} / \mathrm{mL}=\mathrm{D}^{\mathrm{n}} \times 1000 / \mathrm{P}$ 


\subsection{EXTRAÇÃO DO DNA}

As bactérias foram inicialmente inoculadas em meio MRS caldo a $37^{\circ} \mathrm{C}$ por 18 horas. Após, uma alíquota foi transferida com a alça de níquel para uma placa contendo MRS sólido. Incubada a $37^{\circ} \mathrm{C}$ por 24 horas. Uma colônia foi retirada da placa e adicionada a um eppendorf contendo $50 \mu$ lde água destilada estéril. Foi agitada rapidamente no vórtex e levada ao termociclador (BIOER), sob as seguintes condições: 30 ciclos de $97^{\circ} \mathrm{C}$ por 1 minuto, $94^{\circ} \mathrm{C}$ por 30 segundos e $72^{\circ} \mathrm{C}$ por 30 segundos. Posteriormente, foi mantido sob refrigeração a $-20^{\circ} \mathrm{C}$ por 30 minutos e armazenado sob a mesma temperatura.

\subsection{REAÇÃO DA CADEIA POLIMERASE (PCR) E} ELETROFORESE

A PCR com volume total de $15 \mu$ foi realizada para 0 gênero Enterococcus. Para a reação foram adicionados $7,5 \mu \mathrm{l}$ do kit PCR master mix $2 x, 2 \mu \mathrm{l}$ dos primers ENT1 5' TACTGACAAA CCATTCATGATG 3' e ENT2 5' AACTTCGTCACCAACGCGAAC 3' (KE et al., 1999), $2 \mu$ l de DNA e 3,5 $\mu$ l de água ultrapura. 0 controle positivo foi realizado com uma cepa pertencente ao gênero Enterococcus e o controle negativo sem a presença do DNA. As condições da reação foram as seguintes: desnaturação inicial de $95^{\circ} \mathrm{C}$ por 5 minutos. Posteriormente, 35 ciclos de $95^{\circ} \mathrm{C}$ por 1 minuto para a desnaturação, $55^{\circ} \mathrm{C}$ por 30 segundos para 0 anelamento, $72^{\circ} \mathrm{C}$ por 30 segundos para a extensão e extensão final de $72^{\circ} \mathrm{C}$ por 5 minutos.

Os produtos da amplificação foram mantidos a $-20^{\circ} \mathrm{C}$ até a realização da eletroforese em gel de agarose $0,7 \%$ e coradas com corante fluorescente Gel Red (BIOTIUM), para visualização das bandas de DNA.

\section{RESULTADOS E DISCUSSÃ0}

\subsection{RESISTÊNCIA AOS VALORES DE BAIXO pH E PRESENÇA DE SAIS BILIARES}

A sobrevivência das BAL foi estudada simulando as condições do trato gastrointestinal quanto ao pH baixo e à presença de sais biliares, e os resultados estão apresentados nas Tabelas 1 e 2. Também podem ser observados nas Figuras 1 e 2.

De acordo com a Tabela 1 observa-se que 0 pH 2,5 influenciou na sobrevivência das BAL independentemente do tempo de exposição. Esse resultado era esperado, pois $0 \mathrm{pH}$ ácido representa uma barreira para as bactérias permanecerem viáveis.

Entretanto, apesar do $\mathrm{pH}$ adverso, foram encontradas: 1 BAL com crescimento de $1,4 \times 10^{5} \mathrm{UFC} / \mathrm{mL}$ após 3 horas de exposição ao pH ácido. Portanto, podemos concluir que 4 BAL mantiveram-se viáveis, com crescimento médio superior a $4 \times 10^{1} \mathrm{UFC} / \mathrm{ml}$ durante as 3 horas de exposição às condições ácidas que simulam 0 estômago.

Tabela 1. Efeito do suco gástrico simulado em $\mathrm{pH} 2,5$ na viabilidade de 11 BAL durante a incubação de 0,1 e 3 horas

\begin{tabular}{cccc}
\hline \multirow{2}{*}{$\mathbf{N}^{\circ}$ das cepas } & \multicolumn{3}{c}{$\begin{array}{c}\text { Contagem final } \\
\left(\mathbf{U F C} / \mathbf{m L}^{-1}\right)\end{array}$} \\
\cline { 2 - 4 } & $\mathbf{0 h}$ & $\mathbf{1 h}$ & $\mathbf{3 h}$ \\
\hline $\mathbf{6 4}$ & $5,4 \times 10^{4}$ & $6,5 \times 10^{2}$ & $4 \times 10^{1}$ \\
$\mathbf{7 8}$ & $6,8 \times 10^{4}$ & $5,5 \times 10^{2}$ & --- \\
$\mathbf{7 9}$ & $1,9 \times 10^{4}$ & --- & --- \\
$\mathbf{8 5}$ & $2,9 \times 10$ & $6,5 \times 10^{2}$ & --- \\
$\mathbf{9 1}$ & $1,8 \times 10^{4}$ & --- & --- \\
$\mathbf{6 7}$ & ---- & $6 \times 10^{3}$ & $4,8 \times 10^{2}$ \\
$\mathbf{2 3}$ & $1,4 \times 10^{5}$ & $1,6 \times 10^{3}$ & --- \\
$\mathbf{2 4}$ & $1,2 \times 10^{5}$ & --- & $1,4 \times 10^{5}$ \\
$\mathbf{2 0}$ & --- & --- & --- \\
$\mathbf{2 2}$ & $1 \times 10^{3}$ & $1 \times 10^{2}$ & --- \\
$\mathbf{2 1}$ & $2,9 \times 10^{4}$ & $2,8 \times 10^{3}$ & INC. \\
\hline
\end{tabular}




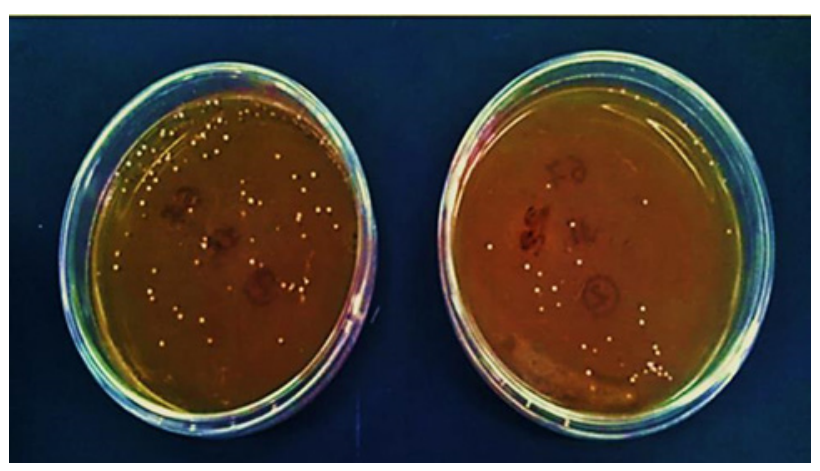

Figura 1. Efeito do suco gástrico simulado em pH 2,5 da BAL 67 em duplicata após 1 hora de exposição

As BAL que sobreviveram ao $\mathrm{pH} \mathrm{2,5} \mathrm{foram}$ utilizadas para a etapa seguinte com os sais biliares. Na Figura 3, observamos que a viabilidade celular foi mantida pelas 4 BAL analisadas. As BAL apresentaram crescimento superior a 2,6 $610^{3}$ após 4 horas de exposição aos sais biliares. Assim, podemos inferir que as $4 \mathrm{BAL}$ analisadas exibiram eficiência na sobrevivência nas condições simuladas do intestino. Esse comportamento é desejável em espécies bacterianas para serem consideradas como probióticos pelas condições de estresse encontradas no trato gastrointestinal. As bactérias probióticas são consumidas de forma oral e devem ser capazes de sobreviver as condições de pH ácido e presença a sais de bile no estômago e intestino, respectivamente, colonizando 0 intestino temporariamente e proporcionando benefícios. Com referência aos microrganismos probióticos, as 4 BAL mostraramse viáveis para colonizar a região do estômago e intestino. Os resultados encontrados estão de acordo com o observado por Vinderola e Reinheimer (2003), pois bactérias ácido lácticas probióticas apresentaram maior resistência a pH baixo que outras bactérias ácido lácticas. Isto sugere a possibilidade de utilização dessas bactérias potencialmente probióticas.
Tabela 2. Efeito simulado das condições do intestino em pH 8,0 ajustado com $0,5 \%$ de sais de bile sobre viabilidade de $4 \mathrm{BAL}$ durante a incubação de 0, 2 e 4 horas

\begin{tabular}{cccc}
\hline$N^{\circ}$ Cepas & \multicolumn{3}{c}{$\begin{array}{c}\text { Contagem final } \\
\text { (UFC/mL-1) }\end{array}$} \\
\cline { 2 - 4 } & Oh & $\mathbf{2 h}$ & $\mathbf{4 h}$ \\
64 & $1,5 \times 107$ & $6,5 \times 10^{6}$ & $2,6 \times 10^{5}$ \\
$21 \mathrm{~A}$ & $6,5 \times 10^{6}$ & $2,5 \times 10^{6}$ & $9 \times 10^{4}$ \\
$24 \mathrm{~A}$ & $1 \times 10^{6}$ & $1,6 \times 10^{6}$ & $9,6 \times 10^{5}$ \\
67 & $5 \times 10^{6}$ & $4,7 \times 10^{6}$ & $1,3 \times 10^{6}$ \\
\hline
\end{tabular}

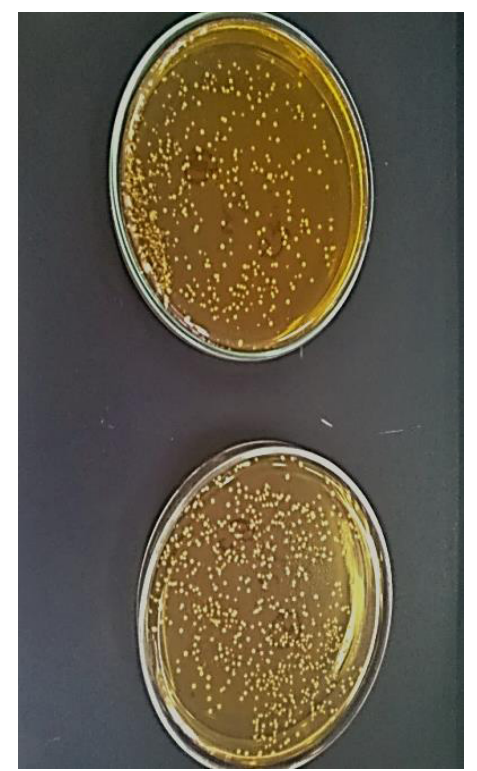

Figura 2. Efeito simulado das condições do intestino em $\mathrm{pH}$ 8,0 ajustado com $0,5 \%$ de sais de bile sobre viabilidade em duplicata da BAL 67 após 4 horas

\subsection{ATIVIDADE ANTIMICROBIANA}

As mesmas BAL avaliadas quanto ao efeito antagônico foram analisadas para a atividade antimicrobiana por produção de substâncias liberadas no sobrenadante. Os resultados estão apresentados na Tabela 3. 
Tabela 3. Atividade antimicrobiana do sobrenadante de BAL isoladas de queijo de coalho artesanal em condições variadas determinadas pelo método de diluição crítica

\begin{tabular}{l|c|c}
\hline \multirow{2}{*}{\multicolumn{1}{c}{ BAL indicadoras }} & \multicolumn{2}{c}{$\begin{array}{c}\text { Bacteriocinas UA/ } \\
\mathbf{m L}^{-1}\end{array}$} \\
\cline { 2 - 3 } & $\mathbf{2 1} \mathbf{A}_{\mathrm{A}}$ & $\mathbf{2 4}{ }_{\mathrm{A}}$ \\
\hline Escherichia coli ATCC 25922 & 27 & 27 \\
Klebsiella pneumoniae ATCC 29665 & 427 & 107 \\
Pseudomonas aeruginosa ATCC 27853 & 107 & 53 \\
Enterococcus faecalis ATCC 6057 & 427 & 427 \\
Bacillus subtilis ATCC 6633 & 27 & 27 \\
Staphylococcus aureus ATCC 6538 & 107 & 107 \\
Listeria innocua ATCC 33090 & 53 & 53 \\
\hline
\end{tabular}

*Unidade arbitrária de bacteriocina por mililitro $\left(\mathrm{UA} / \mathrm{mL}^{-1}\right)=$ recíproca da maior diluição que apresentou inibição.

A BAL $21_{A}$ demonstrou ser mais efetiva contra as bactérias Klebsiella pneumoniae e Pseudomonas aeruginosa. Em todos os casos, observou-se que os sobrenadantes foram eficazes na inibição das bactérias indicadoras. As substâncias com propriedades antimicrobianas produzidas pelas bactérias ácido láticas apresentaram características de interesse, após a incubação por 24 horas. Estas foram ativas contra Klebisiella pneumonae, Enterococcus faecalis, Staphylococcus aureus, Escherichia coli e Listeria inoccua. Inferimos que as substâncias antimicrobianas produzidas sejam bacteriocinas.

Bacteriocinas de bactérias Gram-positivas, incluindo as que são produzidas por bactérias ácido lácticas (BAL), têm atraído grande atenção por causa do seu status GRAS (Generally Recognized as Safe) e do seu uso potencial como aditivo seguro para a conservação de alimentos, podendo inibir o crescimento de bactérias patogênicas Gram-positivas, leveduras e algumas espécies de bactérias Gram-negativas (CLEVELAND; MONTVILLE; CHIKINDAS, 2001; DHEWA, 2012). A produção de bacteriocinas é benéfico para 0 uso como probiótico, pois inibe 0 crescimento de microrganismos indesejáveis na microbiota intestinal do ser humano e de animais.

\subsection{CARACTERIZAÇÃO MOLECULAR}

As BAL 21 e 24 foram positivas para 0 gênero Enterococcus como visto na Figura 4.

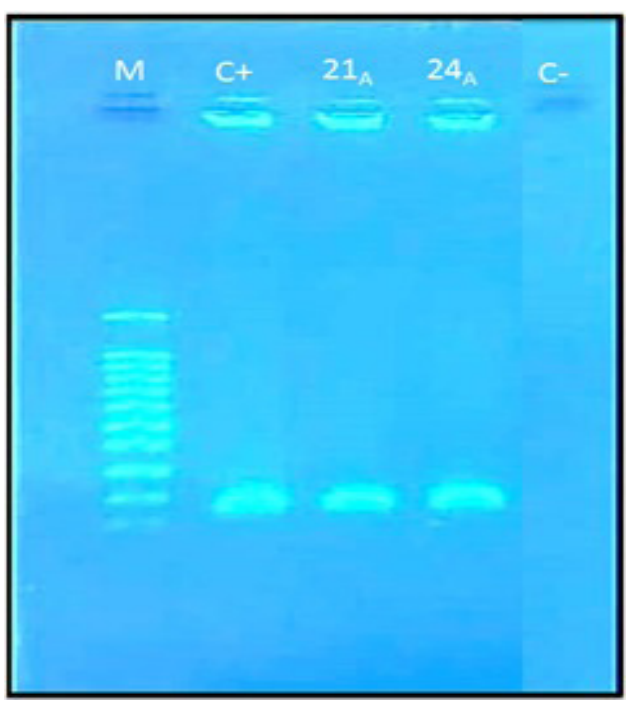

Figura 4. Eletroforese em gel de agarose do produto da PCR amplificado com os produtos dos primers ENT1 e ENT2 específicos para Enterococcus. $\mathrm{M}=$ marcador molecular (ladder), $\mathrm{C}+=$ Controle positivo e $\mathrm{C}-=$ Controle negativo.

\section{CONCLUSÃO}

A caracterização probiótica é extremamente necessária, pois não são todas as BAL que apresentam essas características, por isso os testes são essenciais para a segurança do consumidor. Das 11 bactérias isoladas da cidade de Arcoverde-PE apenas duas foram eficientes para a maioria dos testes demonstrando o seu potencial probiótico. A identificação como pertencentes ao gênero Enterococcus, que faz parte do grupo probiótico de acordo com a ANVISA acentua sua caracterização como um probiótico. Portanto, percebemos que bactérias isoladas do queijo de coalho pernambucano representam importante fonte de microrganismos benéficos para a tecnologia de alimentos e saúde humana e animal. Estudos posteriores são necessários para assegurar a total segurança do produto. 


\section{REFERÊNCIAS}

ARGYRI, A. A. et al. Selection of potential probiotic lactic acid bacteria from fermented olives by in vitro tests. Food Microbiology, v. 33, n. 2, p. 282-91, apr. 2013. DOI: 10.1016/j.fm.2012.10.005. Acesso em: 31 maio 2019.

\section{ANVISA. Substâncias bioativas e probióticos} isolados com alegação de propriedades funcionais e ou de saúde. 2018. Disponível em: http://www.in.gov.br/materia/-/asset_ publisher/Kujrw0TZC2Mb/content/id/34379969/ do 1-2018-07-27-resolucao-da-diretoriacolegiada-rdc-n-243-de-26-de-julhode-2018-34379917. Acesso em: 31 maio 2019.

AXELSSON, L. Lactic acid bacteria: classification and physiology. In: SALMINEN, S. Lactic acid bacteria: microbiology and functional aspects. New York: Marcel Decker, 1998. p. 30.

BERESFORD, T. P.; FITZSIMONS, N. A.; BRENNAN, N. L.; COGAN, T. M. Recents advances in cheese microbiology. International Dairy Journal, v. 11, n. 4-7, p. 259-274, jul. 2001.

\section{CASTILLO, F. M. Produção de bacteriocina por} Bifidobacterium lactis a partir de leite desnatado. 2013. 107 f. Dissertação (Mestrado em Tecnologia Bioquímico-Farmacêutica) - Faculdade de Ciências Farmacêuticas, Universidade de São Paulo, São Paulo, 2013.

CAVALCANTE, J. F. et al. Lactobacillus capillatus sp., a motile Lactobacillus specie isolated from stinky tofu brine. International Journal of Systematic Evolutionary Microbiology, v. 58, n.11, p. 25552559, nov. 2008.

CLEVELAND, J.; MONTVILLE, T.; NES, I. F.; CHIKINDAS, M. L. Bacteriocins: safe, natural antimicrobials for food preservation. International Journal of
Food Microbiology, v. 71, n. 1, p. 1-20, 2001. Disponível em: http://dx.doi.org/10.1016/S01681605(01)00560-8. Acesso em: 23 maio 2019.

DEEGAN, L. C.; COTTER, P. D.; HIL, C.; ROSS, P. Bacteriocins: biological tools preservation and shelflife extension. International Dairy Journal, v. 16, n. 9, p. 1058-1071, sep. 2006.

DHEWA, T. Screening, production purification and potential use of bacteriocins from lactic acid bacteria of meat and dairy food origin. In: INTERNATIONAL CONFERENCE ON NUTRITION AND FOOD SCIENCES, 2012, Singapore. Proceedings [...]. Singapore: IACSIT Press, 2012. v. 39, p. 35-41.

DIAS, G. M. P. Potencial tecnológico de bactérias ácido láticas isoladas de queijo de coalho artesanal produzido no município de Venturosa Pernambuco. 2014. Tese (Doutorado em Ciências Biológicas) - Programa de Pós-Graduação em Ciências Biológicas, Universidade Federal de Pernambuco, Recife, 2014.

ESCOBAR, C. A. M. Avaliação dos pontos críticos na produção de queijo de coalho em Pernambuco.

Revista do Instituto de Laticínios Cândido Tostes, v. 56, n. 321, p. 248-256, 2001.

FOOD AND AGRICULTURE ORGANIZATION OF THE UNITED NATIONS; WORLD HEALTH ORGANIZATION. Guidelines for the evaluation of probiotics in food. London: FAO: WHO, 2002.

HOFVENDAHL, K.; HÄGERDAL-HAHN, B. Factors affecting the fermentative lactic acid production from renewable resources. Enzyme and Microbial Technology, v. 26, n. 2-4, p. 87-107, fev. 2000.

KE, D. et al. Development of a PCR assay for rapid detection of enterococci. Journal of Clinical Microbiology, v. 37, n. 11, p. 3497-3503, nov. 1999. 
MAYR-HARTING, A.; HEDGES, A. J.; BERKELEY, R. C. W. Methods for studying bacteriocins. In: NORRIS, J. R.; RIBBONS, D. W. (ed.). Methods in microbiology. New York: Academic Press Inc., 1972. p. 315-422.

OLIVEIRA-SERQUEIRA, T. C. G.; RIBEIRO, C. M.; GOMES, M. I. F. V. Probiotics as potential biotherapeutic agentes targeting intestinal parasites. Ciência Rural, v. 38, p. 2670-2679, 2008.

SETTANNI, L.; MOSCHETTI, G. Non-starter lactic acid bacteria used to improve cheese quality and provide health benefits. Food Microbiology, v. 27, p. 691697, 2010.

VINDEROLA, C. G.; REINHEIMER, J. A. Lactic acid starter and probiotic bacteria: a comparative "in vitro" study of probiotic characteristics and biological barrier resistance. Food Res. Int., v. 36, p. 895-904, 2003.

Recebido em: 08/04/2019

Aceito em: 31/05/2019 